2002s-06

\title{
Information Asymmetry, Insurance, and the Decision to Hospitalize
}

Åke Blomqvist, Pierre Thomas Léger

Série Scientifique

Scientific Series

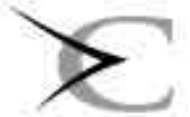

CIRANO

Montréal

Janvier 2002 


\section{CIRANO}

Le CIRANO est un organisme sans but lucratif constitué en vertu de la Loi des compagnies du Québec. Le financement de son infrastructure et de ses activités de recherche provient des cotisations de ses organisationsmembres, d'une subvention d'infrastructure du ministère de la Recherche, de la Science et de la Technologie, de même que des subventions et mandats obtenus par ses équipes de recherche.

CIRANO is a private non-profit organization incorporated under the Québec Companies Act. Its infrastructure and research activities are funded through fees paid by member organizations, an infrastructure grant from the Ministère de la Recherche, de la Science et de la Technologie, and grants and research mandates obtained by its research teams.

\section{Les organisations-partenaires / The Partner Organizations}

-École des Hautes Études Commerciales

-École Polytechnique de Montréal

-Université Concordia

-Université de Montréal

-Université du Québec à Montréal

-Université Laval

-Université McGill

-Ministère des Finances du Québec

-MRST

-Alcan inc.

- AXA Canada

-Banque du Canada

-Banque Laurentienne du Canada

-Banque Nationale du Canada

- Banque Royale du Canada

- Bell Canada

- Bombardier

-Bourse de Montréal

-Développement des ressources humaines Canada (DRHC)

-Fédération des caisses Desjardins du Québec

-Hydro-Québec

-Industrie Canada

-Pratt \& Whitney Canada Inc.

-Raymond Chabot Grant Thornton

-Ville de Montréal

(C) 2002 Åke Blomqvist et Pierre Thomas Léger. Tous droits réservés. All rights reserved. Reproduction partielle permise avec citation du document source, incluant la notice $($ ).

Short sections may be quoted without explicit permission, if full credit, including (C) notice, is given to the source.

Ce document est publié dans l'intention de rendre accessibles les résultats préliminaires de la recherche effectuée au CIRANO, afin de susciter des échanges et des suggestions. Les idées et les opinions émises sont sous l'unique responsabilité des auteurs, et ne représentent pas nécessairement les positions du CIRANO ou de ses partenaires.

This paper presents preliminary research carried out at CIRANO and aims at encouraging discussion and comment. The observations and viewpoints expressed are the sole responsibility of the authors. They do not necessarily represent positions of CIRANO or its partners.

ISSN 1198-8177 


\title{
Information Asymmetry, Insurance, and the Decision to Hospitalize*
}

\author{
Åke Blomqvist ${ }^{\dagger}$, Pierre Thomas Léger ${ }^{*}$
}

\author{
Résumé / Abstract
}

À l'aide d'un modèle théorique dans lequel patients et médecins doivent choisir la quantité de service à utiliser ainsi que celui, de l'omnipraticien ou du spécialiste œuvrant à l'hôpital, qui fournira ces services, nous analysons différents mécanismes d'incitation agissant sur l'offre et la demande. Nous étudions essentiellement deux modes d'organisation : le système conventionnel de rémunération à l'acte et le système de gestion intégrée des soins avec une rémunération per capita; à la fois en présence et en l'absence d'asymétrie d'information. Nous obtenons comme résultat qu'à certaines conditions plausibles, l'optimum de second-rang auquel mène le système de gestion intégrée est supérieur à celui que donne le système conventionnel de rémunération à l'acte qui répercute une partie des coûts sur l'utilisateur.

In a theoretical model, we analyze the effects of various kinds of demand-and supply-side incentives in the context of a model in which patients and doctors must decide not only on an aggregate quantity of health services to use in treating various kinds of illness, but also have a choice between different kinds of providers (in particular, outpatient services rendered by primary-care physicians or inpatient services provided by hospital-based specialists). We present two broad models, the traditional fee-for-service payment scheme and a managed care setup where physicians are paid via capitation, and analyze them both with and without information asymmetry. We find that under certain plausible conditions, second-best optimal managed care plans may dominate second-best optimal conventional plans that rely on cost control through demand-side cost sharing.

Mots-clés : Omnipraticiens, Spécialistes, Hospitalisation, Assurance, Paiements à l'acte et per capita, Asymétrie d'information

Keywords : Primary Care, Specialty Care, Hospitalization, Insurance, HMOs, Capitation, Asymmetric Information

JEL : I1

\footnotetext{
* We thank seminar participants at McGill, National University of Singapore, HEC Montréal, CIRANO, the CEA annual meeting (Montreal), the SCSE annual meeting (Québec) and the $5^{\text {th }}$ Biennial Conference on the Industrial Organization of Health Care (sponsored by the VA Management Group and the ISP, Department of Economics, Boston University), especially our discussant Lise Rochaix. Léger thanks HEC Montréal (Fond Mercure) and SSHRC for financial support. The usual caveats apply.

${ }^{\dagger}$ University of Western Ontario

${ }^{*}$ HEC Montréal et CIRANO
} 


\section{Introduction}

Much of the health economics literature has focussed on the effects of different payment mechanisms and insurance schemes on the utilization of medical services. In the presence of conventional service benefit insurance, individuals will want to use medical care beyond efficient levels (the traditional moral hazard problem). Furthermore, physicians that are paid for each service they provide (in a fee-for-service system) may not only be willing to supply inefficiently large volumes of care, but may also have incentives to encourage utilization (the problem of supplier-induced demand). In order to reduce the problems associated with moral hazard and supplier-induced demand, insurers have used demand-side incentives (such as patient cost-sharing through co-insurance and deductibles), as well as supply-side incentives aimed at providers (such as paying physicians through salary or capitation, or hospitals through episode-based prospective reimbursement).

Formal models dealing with these issues have generally been specified so as to involve only one type of medical care. That is, they have abstracted from the fact that the health services sector produces many types of care, using a variety of different kinds of inputs. For example, certain kinds of disease may be treated through a combination of physician services and pharmaceuticals. In other cases, there may be substitutability between outpatient services provided by primarycare physicians and services provided by hospital-based specialists. Although the latter may be necessary for individuals that suffer from particularly complex and severe forms of illness, excessive use of specialist and hospital care may be inefficient and inappropriate. First, for certain kinds of illness, primary-care physicians may be able to provide treatment at lower cost. Furthermore, specialist in-hospital care is more likely to be invasive and risky, and thus should only be used when 'medically warranted' (Frank and Clancy, 1997). Providing incentives to ensure that patients use the appropriate type of care is thus important both from a health perspective, and for economic reasons. In this paper, we analyze the effects of various kinds of demand- and supply-side incentives in the context of a model in which patients and doctors must decide not only on an aggregate quantity of health services to use in treating various kinds of illness, but also have a choice between different kinds of providers, in particular, outpatient services rendered by primary-care physicians or inpatient services provided by hospital-based specialists.

Although theoretical work on the economics of medical referrals is limited and quite recent, 
there is a growing empirical literature that has examined physician referral patterns. ${ }^{1}$ Overall, 4.5 per cent of visits to primary care physicians in the US result in a referral (Frank and Clancy, 1997). ${ }^{2}$ Furthermore, although hospital admissions are relatively rare (approximately 10 per cent of individuals in the Rand Study experienced one or more admissions in a year), hospitalization episodes are very costly so that the cost of hospital care accounts for a large portion of health care costs. ${ }^{3}$ On average, each referral results in US\$3,000 in hospital charges and professional fees (Glenn et al., 1987). Potentially important factors that may influence the use of specialist and hospital care include whether or not patients are allowed to seek such care on their own (that is, without a referral from a primary-care provider). Although many health care systems and managed-care plans prohibit patient self-referrals to specialty care and in-hospital care, others do not, and it has been estimated that in the US, 30 to 50 per cent of all specialist consultations take place as a result of self-referrals (Forest and Reid, 1997). In American managed care plans, a common device for affecting the use of hospital services is to require a 'second opinion' before approval is given for hospitalization. This may be one reason that HMO patients are less likely to be hospitalized compared to their non-HMO counterparts (Newhouse, 1993).

The empirical work provides some evidence that the rate of hospitalization is influenced by incentives both on the supply side and on the demand side. With respect to supply-side factors, there is evidence to suggest that physicians who are paid on the basis of fee for service are less likely to refer patients than are physicians paid through capitation (Grembowski et al., 1998). Furthermore, in cases where primary-care physicians have a role as gatekeepers (that is, a referral from a primary-care doctor is required for a patient to receive treatment by a specialist or in hospital), it has been found that gatekeepers who face financial risks when they refer (that is, who have to pay some of the cost of specialist and hospital care used by their patients) are less likely to refer to specialists (Martin et al., 1989; Hurley et al, 1991). Patients also appear to respond to demand-side incentives when making decisions with respect to specialist care. Shortell and Vahovich (1975) find that patients with higher third-party coverage are more likely to use specialist

\footnotetext{
${ }^{1}$ Theoretical work on referrals include Shortell (1972), Bradford and Martin (1960), Glazer and McGuire (1992) as well as related work by Pauly (1979) and Wolinsky (1993).

${ }^{2}$ Based on American survey data from the National Ambulatory Medical Care Survey (NAMCS) for the years 1985 to 1992.

${ }^{3}$ For example, in the Rand 'Free Plan' (no co-payments or deductibles), the likelihood of any use of medical care was 86.8 per cent, while the likelihood of one or more admissions was 10.3 per cent. Furthemore, the average total expenditure (per person per year) was $\$ 982$ (1991 dollars) with $\$ 536$ dollars of that in in-patient expenditures (Table 3.2, page 40, Newhouse et al., 1993).
} 
care. Furthermore, persons that belong to a government plan and have supplemental insurance have a higher likelihood of using specialist care than those who do not (Shea et al., 1999). The Rand data also suggests, although weakly, that patient cost-sharing reduces total hospital expenditures (Newhouse et al., 1993).

In this paper, we extend the study of demand- and supply-side incentives to a model in which we explicitly consider the interaction between insurance and the choice between primary care and in-hospital care. We find that such a model yields certain new insights for both types of incentives.

With respect to conventional insurance plans in which utilization is influenced by demand-side incentives (patient cost-sharing), we find that the moral-hazard problem associated with overutilization of services from a given provider may be significantly exacerbated because patient cost-sharing will also influence the patient's choice of provider (i.e., their decision to be hospitalized). This effect may be an important one in searching for the optimum degree of patient cost-sharing, and is likely to be particularly significant in assessing the effect of plans in which there is a lower degree of cost-sharing for hospital care because it tends to be used in cases of serious illness. An interesting finding is that managed-care plans that use patient cost-sharing as the principal cost control mechanism, but control hospital utilization through a second-opinion requirement, may yield a substantially more efficient pattern of care than plans that rely on patient cost sharing alone.

In some models that explore the effects of different insurance arrangements in an environment of information asymmetry between providers and patients, it has been shown that paying primarycare physicians through capitation may be efficient in the sense that it reduces excessive health services utilization (Hillman et al, 1989; Wolfe et al., 1992, Léger, 2000). However, this need not hold in a model such as ours when primary-care physicians advise patients not only regarding the use of their own services, but also regarding the advisability of the services of other providers such as in-hospital care provided by a specialist. Indeed, primary-care physicians paid via capitation have an incentive to over-refer to hospital, since this may reduce the physician's workload without affecting his or her income. On the other hand, primary-care physicians paid via fee for service may under-refer to hospital (in comparison with an efficient rate) since services provided by hospitalbased specialists do not generate additional income. We analyze consequences of both kinds of incentives, and possible mechanisms for overcoming them, in our model below.

The remainder of the paper is organized as follows. In the second section, we consider the case of conventional insurance and physician payment through fee for service. We analyze both the case in 
which there is full information in the sense that patients are as well informed about their illness, and the consequences of treatment as their doctors, and the case with imperfect information in which doctors are better informed than their patients. In Section 3, we then consider managed-care plans in which doctors are paid through capitation or salary, again with alternative assumptions with respect to the degree of information asymmetry between patients and doctors. Conclusions are drawn in Section 4.

\section{The Fee For Service Model}

\subsection{Fully informed patients}

In the first version of the model, we assume that the patient fully observes his or her illness severity and chooses both the quantity of care and the provider, at given prices (i.e., from a 'price list' per episode and quantity of services supplied from each provider). We also assume that patients can purchase insurance prior to the revelation of illness severity, at an actuarially fair price. Once illness severity is revealed, patients will choose whether or not to buy any care at all, to buy care from a primary-care physician (henceforth referred to as a GP), or to enter hospital to be treated by a hospital-based specialist. In the latter two cases, they also have to decide on what quantity of services to utilize.

Although we assume that both types of providers (GP and hospital based specialists) may treat the patient for any illness severity, their relative efficiency in doing so depends on the illness severity. Specifically, we model each episode of treatment as involving two types of cost, one which is a fixed amount for each episode, and one which varies with the quantity of treatment (measured in efficiency units) that is provided. Treatment in hospital is assumed to have a higher fixed cost per episode but a lower variable cost per unit of effective treatment once this fixed cost has been incurred (relative to care provided by a GP). The episode-specific fixed cost may be thought of as consisting of things like the administrative costs associated with hospital admission, as well as diagnostic testing that typically precede treatment received in hospital. Some of this fixed cost may be non-monetary and be born by patients directly. For example, in-hospital treatment may require larger amounts of travel expenditure and time off work than GP care. We assume that pricing is competitive in the sense that the costs charged by providers to the patients and their insurers reflect the real opportunity costs of producing the corresponding services. ${ }^{4}$

\footnotetext{
${ }^{4}$ It is important to disting uish between episode-specific fixed costs, and costs that are fixed for the provider in the
} 
Formally, we specify a model in which the representative consumer $i$ 's utility depends on consumption $X$ and health $H$, as well as on a state variable $\theta$ which we interpret as an illness severity variable. Ex ante, the patient does not know what $\theta$ is going to be, though it is assumed that its cumulative distribution function $F(\theta)$ is known. In this section, we also assume that once nature has generated a value of $\theta$, the patient knows what it is. Given $\theta$, the patient maximizes utility by choosing a provider $j$ where $j$ may be either $G$ (for general practitioner) or $S$ (for in-hospital care provided by a specialist); we also assume that the patient can choose no care at all $(j=N)$. If $j$ is $G$ or $S$, the patient also chooses a quantity $q^{j}$. In this section, the patient is supposed to have a conventional insurance contract with a co-payment rate of $\beta$ and premium $\alpha$. We assume that insurance is provided in a competitive market. The $\beta$ and its corresponding $\alpha$ which will prevail in equilibrium will than be those that maximize expected utility.

In each state, the patient receives a (state-independent) income $I$. Since $\theta$ is known ex post and utility is maximized in each state, ex ante utility is maximized as well, so the patient solves the problem:

$$
\max _{q^{j}, j} \int_{\theta} U[X(\theta), H(\theta)] d F(\theta) ; \quad j=G, S, N
$$

subject to

$$
\begin{gathered}
X=I-\beta\left(F^{j}+c^{j} q^{j}(\theta)\right)-\alpha \\
H=q^{j}(\theta)-\theta
\end{gathered}
$$

and where,

$$
\alpha=(1-\beta) \int_{\theta}\left[F^{j}+c^{j} q^{j}(\theta)\right] d F(\theta)
$$

It is important to note that the fixed cost $(F)$ and the marginal cost $(c)$ are provider-type dependent, and, by assumption, $F^{S}>F^{G}$ but $c^{S}<c^{G}$.

sense that they depend neither on the number of treatment episodes nor on the quantity of treatment supplied. The analysis in this paper focusses on the former. 
To solve the above problem, the patient finds quantities $q^{j}$ that are optimal when the provider is $G$ or $S$, and then compares the level of maximized utility, represented by the provider-specific indirect utility function $V^{j}$, for each provider type (including no care at all).

When $j=G$ or $S$, the first order condition for the provider-specific optimal value of $q^{j}$ satisfies:

$$
U_{X}\left(-\beta c^{j}\right)+U_{H}=0
$$

Given (5) it is easy to show that:

Proposition 1 Conditioning on purchasing some positive amount of care (that is, having paid the co-payment with respect to the fixed cost), the quantity of care demanded for a particular type of care (either GP or in-hospital care) is increasing in illness severity for $j=G$ or $S$ if $U_{X H}=U_{H X} \geq 0$ (sufficient but not necessary), i.e.

$$
\frac{\partial q^{j}}{\partial \theta}>0
$$

Proof: See Appendix 1.

Proposition 2 For a given choice of provider, utility is decreasing in illness severity, i.e.

$$
\frac{\partial V^{j}}{\partial \theta}<0
$$

for $j=G$ or $S$ and $N$.

Proof: By assumption, utility is decreasing in illness severity for a given $q^{j}$. Thus for individuals who consume no care, utility is decreasing in $\theta$. It is also decreasing for $j=G$ or $S$. Suppose that this were not the case. Suppose that $V^{j}(\widehat{\theta}(\widehat{q}))>V^{j}(\widetilde{\theta}(\widetilde{q}))$ where $\widehat{\theta}>\widetilde{\theta}$ and $\widehat{q}>\widetilde{q}$. However, this would imply that $V^{j}(\widetilde{\theta}(\widehat{q}))>V^{j}(\widetilde{\theta}(\widetilde{q}))$ which is a contradiction given that $\widetilde{q}$ is the utility maximizing quantity of care for illness severity $\widetilde{\theta}$.Q.E.D.

If the choice of 'No care' is ever optimal, it will be at the lowest values of $\theta$ (i.e., for the patient with least severe illness). Also, if care provided by both $G$ and $S$ is part of the optimal path, $G$ will be chosen at lower values of $\theta$ and $S$ at higher values. ${ }^{5}$

\footnotetext{
${ }^{5}$ It may be the case that for a given illness distribution and cost functions that patients will either (i) never consult a GP (i.e., go from not consuming care to being hospitalized), or (ii) are never hospitalized. We exclude these two cases in the discussion.
} 
To see this, let $\theta^{C 1}$ denote the critical value where illness severity is such that the consumer is indifferent between consuming 'no care' and consulting a GP. Similarly, let $\theta^{C 2}$ denote the critical value where illness severity is such that the consumer is indifferent between consulting a GP and being hospitalized. The First Order Conditions for optimal choices of $\theta^{C 1}$ and $\theta^{C 2}$ are given by (8) and (9) respectively:

$$
\begin{gathered}
U^{N} \equiv U\left(I-\alpha,-\theta^{C 1}\right)=U\left(I-\alpha-\beta\left(F^{G}+c^{G} q^{G *}\right), q^{G *}-\theta^{C 1}\right) \equiv U^{G} \\
U^{G} \equiv U\left(I-\alpha-\beta\left(F^{G}+c^{G} q^{G *}\right), q^{G *}-\theta^{C 2}\right)=U\left(I-\alpha-\beta\left(F^{S}+c^{S} q^{S *}\right), q^{S *}-\theta^{C 2}\right) \equiv U^{S}
\end{gathered}
$$

For a diagramatic consideration of these conditions consider figure 1. Each of the curves $D(\theta)$ is a compensated demand curve associated with the utility-maximizing choice of $q^{G}$ (that is, when $j=G$ ). For low values of $\theta$, the question whether the person will utilize any care depends on whether the area under the compensated demand curve above $\beta c^{G}$ (the consumer surplus associated with the optimal choice of $q^{G}$ ) is larger or smaller than $\beta F^{G}$. For larger values of $\theta$, the choice between $S$ (in-hospital care) and $G$ (GP care) depends on the incremental consumer surplus associated with lowering the consumer's effective price at the margin from $\beta c^{G}$ to $\beta c^{S}$, in comparison with the difference $\beta\left(F^{S}-F^{G}\right)$. At the critical $\theta$, the consumer is just indifferent between the two, so that denoting by $U^{G}$ and $U^{S}$ the optimized utility when receiving services from $G$ and $S$ respectively, it must be true that $U^{S}=U^{G}$, so that the optimal quantities are at $q^{S}$ and $q^{G}$ in figure 1 , respectively.

$<$ Insert figure 1 here $>$

It is interesting to note that at $\theta^{C 2}$, the quantity of efficiency units of care purchased from a GP $\left(q^{G}\right)$ is less than that purchased when in hospital $\left(q^{S}\right)$. That is, at the point where the patient is just indifferent between GP care and hospitalization, the consumption of efficiency units of care purchased increases in a discontinuous manner.

We can now prove:

Proposition 3 In the neighbourhood of the critical value of $\theta^{C 2}$, total expenditures on hospital care is larger than total expenditure on GP care.

Proof: Since the compensated demand curve slopes downward, it must be the case that $q^{S}>q^{G}$. But since $U^{G}=U^{S}$, this means that $X^{G}$ (consumption under GP care) must be larger than $X^{S}$ 
(consumption under Specialty care), which require $F^{S}+c^{S} q^{S}(\theta)>F^{G}+c^{G} q^{G}(\theta)$.

\subsubsection{The effect of insurance on the optimal path (the full information model)}

We now examine the role of insurance in the above model; more specifically, we consider how a change in insurance coverage will alter both the mix and quantities of health services purchased.

Although a decrease in the co-insurance rate (for a given provider type) will lead to greater consumption (the well-know moral hazard problem), a change in insurance parameters may also lead to changes in the optimal path of providers. That is, it is likely to have an effect on the 'critical values' $\theta^{C 1}$ and $\theta^{C 2}$.

Proposition 4 For a given provider, a decrease in $\beta$ (the co-insurance rate) will increase the quantity of care demanded, i.e.

$$
\frac{\partial q^{j}}{\partial \beta}<0
$$

Proof: See Appendix 2.

Proposition 5 For a given insurance premium $\alpha$, a decrease in $\beta$ (the co-insurance rate) will decrease the critical values of $\theta^{C 1}$ and $\theta^{C 2}$, i.e. the critical point where the patient switches from 'no care' to 'GP care' and the critical point where the patient will switch from 'GP care' to 'inhospital care' will both occur at lower severity of illnesses.

Proof: See Appendix 3.

In reality, of course, a lower $\beta$ will cause the insurance premium to rise, which will have an income effect. When this is taken into account, it is no longer necessarily true that the critical values of $\theta^{C 1}$ and $\theta^{C 2}$ will be lower in the new equilibrium with a lower $\beta$. However, the income effect is likely to be small, so that in reality $\theta^{C 1}$ and $\theta^{C 2}$ are likely to fall with reduced cost-sharing. This also implies that, ceteris paribus, patients will be hospitalized more often.

Next we show:

Proposition 6 An insured consumer will choose an inefficiently small critical value $\theta^{C 1}$ at which to switch from 'no care' to 'GP care' and an inefficiently small critical value $\theta^{C 2}$ at which to be hospitalized. 
Proof: Recall that the critical value $\theta^{C 2}$ is characterized by (9). Since the compensated demand curve slopes downwards, $q^{S *}>q^{G *}$. In order for (9) to hold, it must then be the case that $F^{S}+c^{S} q^{S *}>F^{G}+c^{G} q^{G *}$. Now, let $E$ denote the expected utility of the representative consumer. Consider now the effect of a change in the critical value $\theta^{C 2}$ on expected utility, i.e. $\frac{d E}{d \theta^{C 2}}$.

$$
\begin{aligned}
\frac{d E}{d \theta^{C 2}} & =U^{S}-U^{G}+\frac{d E}{d \alpha} \frac{d \alpha}{d \theta^{C 2}} \\
& =0+\frac{\partial E}{\partial \alpha}\left[\left(F^{G}+c^{G} q^{G *}\right)-\left(F^{S}+c^{S} q^{S *}\right)\right](1-\beta)
\end{aligned}
$$

Given that $\frac{\partial E}{\partial \alpha}<0$ and $\left(F^{G}+c^{G} q^{G *}\right)-\left(F^{S}+c^{S} q^{S *}\right)<0, \frac{d E}{d \theta^{C 2}}>0$. The proof for $\frac{d E}{d \theta^{C 1}}$ is analogous. Q.E.D.

Proposition 5 has implications for the efficient degree of cost sharing, or equivalently, the design of a second-best insurance plan. To see this, note that treating $\theta^{C 2}$, for example as an endogous variable, the consumer's expected utility can be written as $E U=E U\left(\beta, \theta^{C 2}, \alpha\left(\beta, \theta^{C 2}\right)\right)$. Differentiating with respect to $\beta$, one obtains:

$$
\frac{d E U}{d \beta}=\left(\frac{\partial E U}{\partial \beta}+\frac{\partial E U}{\partial \alpha} \frac{\partial \alpha}{\partial \beta}\right)+\frac{d \theta^{C 2}}{d \beta}\left(\frac{\partial E U}{\partial \theta^{C 2}}+\frac{\partial E U}{\partial \alpha} \frac{\partial \alpha}{\partial \theta^{C 2}}\right)
$$

The first term within round brackets reflects the standard trade-off between the incremental loss from less complete insurance and the reduction in the conventional moral hazard effect as the degree of cost sharing is increased, holding $\theta^{C 2}$ constant; if $\theta^{C 2}$ were given, it would have to be zero in a second-best optimal plan. However, if (11) is evaluated at the critical value that the consumer would choose for a given value of $\beta$ and $\alpha$, the first term inside the second set of brackets would be zero. Moreover, since $F^{G}+c^{G} q^{G}(\theta)<F^{S}+c^{S} q^{S}(\theta)$, the insurance premium $\alpha$ is decreasing in $\theta^{C 2}$. Therefore if the critical value of $\theta^{C 2}$ is chosen by the consumer, equation (11) would be positive at the value of $\beta$ where the first term in square brackets would be zero (since $\theta^{C 2}$ increases with $\beta$ and $\left.\frac{\partial F U}{\partial \alpha}<0\right)$.

Taking this effect into account, it is clear that the optimum degree of cost sharing is higher when the effect through the choice of critical value $\theta^{C 2}$ is taken into account, than it would be for a fixed $\theta^{C 2}$. Moreover, suppose it were possible for the insurer to verify the value of $\theta$. If this could be done at no cost, an insurance policy that specified optimally chosen values of both $\beta$, and $\theta^{C 2}$ would involve a $\theta^{C 2}$ higher than what consumers themselves would choose at any given $\beta$, but would give 
a higher expected utility than a policy specifying an optimally chosen cost-sharing parameter $\beta$ alone (i.e., it would 'delay' hospitalization but yield a higher expected utility). Managed care plans requiring a second opinion before covering hospitalization, but in other ways similar to conventional insurance, can be regarded as real-world examples consistent with this finding.

The above logic also holds with respect to the critical value $\theta^{C 1}$ at which the consumer would first seek GP care. That is, an insured consumer will choose an inefficiently low level of $\theta^{C 1}$, and the optimum degree of cost-sharing will be higher if the effect of $\beta$ on $\theta^{C 1}$ is taken into account, in comparison with the case where $\theta^{C 1}$ is taken as fixed. If $\theta$ could be costlessly observed by the insurer, imposing an exogenous bound on $\theta^{C 1}$ would also be second-best welfare improving. ${ }^{6}$

\subsection{Fee-for-service model with asymmetric information}

In the preceding section, it was assumed that patients could costlessly and perfectly observe their illness severity $\theta$. In this section, we modify the model by incorporating the idea of information asymmetry between doctors and patients. We do this by introducing the assumption that patients can only imperfectly interpret the symptoms on which they base their estimate of their illness severity.

More precisely, assume that the distribution $F(\theta)$ from which illness severity is drawn is bounded by $\theta^{0}, \theta^{L}$ and is subdivided into $L$ intervals $\left[\theta^{l-1}, \theta^{l}\right], l=1, \ldots, L$. Although the patient does not observe the exact value of $\theta$, we assume that he or she can distinguish between these intervals (classes of illness); that is, the patient knows in which interval his or her true $\theta$ is located. However, there is information asymmetry: A physician can costlessly observe each patient's precise $\theta$ (can costlessly diagnose the patient's illness).

We continue to assume that doctors, both GPs and hospital-based specialists, are paid on the basis of fee for service and that both have an incentive to exploit their superior information in the sense that their net income is higher the more services they provide. We also assume that doctors know the boundaries of the intervals that define the patient's information. In this case doctors always have an incentive to tell patients that their illness severity parameter is at the upper end of the relevant interval. ${ }^{7}$

\footnotetext{
${ }^{6}$ Imposing a $\theta^{C 1}$ (i.e., a point at which th patient may seek general medical care) may be impossible to implement as there can be no gatekeeping to GP care.

${ }^{7}$ Formal models of asymmetric information in medical care include Dranove (1988) and Rochaix (1989). Both authors specify probability distributions that link patients' beliefs about the way they should be treated, to the 'true' underlying illness conditions, and employ models in which the patient's problem is whether to accept or reject a
} 
The above analysis applies in every interval except the one that contains the critical value $\theta^{C 2}$ at which a well-informed patient would switch from treatment by a GP to treatment in hospital. Denote this interval by $r^{2}$. For a patient with any value of $\theta$ in this interval, a GP would have an incentive to tell patients their illness severity was just below $\theta^{C 2}$; a hospital-based specialist, in contrast, would say that it was at the upper end of the interval. Similarly denote by $r^{1}$ the interval which contains $\theta^{C 1}$. In that interval, a GP would have an incentive to tell patients their illness severity was at the upper end of the interval.

Assuming that patients correctly perceive their physicians' incentives, they realize that in reality, their illness severity is unlikely to always be at the upper end of the relevant interval. However, they have no way of finding out what the true value of illness is. As a result, they must decide on the quantity of treatment to receive (and, in the interval $r^{2}$, from what provider), knowing only which interval they are in.

Assuming patients know that distribution function $F(\theta)$, for a given interval $l$, insurance premium $\alpha$, and co-insurance rate $\beta$, the patient maximizes expected utility for the interval by choice of $q_{l}^{j}$. The first order conditions are given by:

$$
\int_{\theta^{l-1}}^{\theta^{l}}\left[U_{X}\left(q_{l}^{j}, \theta\right)\left(-\beta c^{j}\right)+U_{H}\left(q_{l}^{j}, \theta\right)\right] d F(\theta)=0
$$

where, $j=G$ for intervals $l=r^{1}+1, \ldots, r^{2}-1$ and $j=S$ for intervals $l=r^{2}+1, \ldots, L$. For $l=r^{1}$ (that is, the interval that contains $\theta^{C 1}$ ), $j$ may be $N$ or $G$ and for $l=r^{2}, j$ may be $G$ or $S$ depending on which choice yields the higher level of utility at the quantity that maximizes expected utility. As before, an actuarial fairness constraint of type (4) but with a constant quantity $q_{l}^{j}$ in each interval, will hold in equilibrium.

Clearly, expected utility with imperfect information must be lower than for the case where the patient can observe $\theta$. Furthermore, as before, it is now possible to consider the problem of finding the insurance contract $\{\beta, \alpha(\beta)\}$ that is second-best optimal in the sense of balancing appropriately the moral-hazard loss associated with overutilization of health services against the gains from more complete insurance. In solving this problem one would have to take into account

doctor's treatment recommendation, based on their beliefs about their illness condition, and their beliefs about the doctor's information and strategy. The solution depends in part on either the cost of not being treated (Dranove) or of obtaining a recommendation from another doctor (Rochaix). Our approach simplifies the problem both by the way we specify patient beliefs, and because we model the quantity of treatment as being decided by the patient; asymmetric information remains important, however, because it influences the way the patient treats information conveyed by doctors in making the quantity decision. 
that discontinuities in the function $\alpha(\beta)$ may exist at points where the consumer changes from $j=N$ to $j=G$ in $r^{1}$ and from $j=G$ to $j=S$ in $r^{2}$.

\section{Managed care}

In the previous section, we assumed that patients were covered by a conventional insurance plan in which they themselves decided what quantity of services to utilize, given their information about illness severity. Doctors were assumed to be paid on the basis of fee for service, and their role was limited to supplying the quantity the patients decided to utilize, given their insurance contract; the insurer's role was that of a passive payer of bills.

In this section, we consider insurance plans in which the insurer takes a more active role in influencing the services their patients utilize, i.e., managed care plans. We characterize such plans as insurance contracts with no patient cost sharing (that is, the parameter $\beta$ in the preceding section's model is set to zero), but with a specific set of quantities for different illness severities, and critical values $\theta^{C 1}$ and $\theta^{C 2}$ at which coverage will change from no care to GP care and GP care to in-hospital care respectively..$^{8,9}$

\subsection{Perfect information}

Consider first the case where there is perfect information in the sense that the illness severity parameter $\theta$ is costlessly observable to insurers as well as to patients and doctors. In this case, insurers can offer plans of the form $\left\{q^{j}(\theta), \theta^{C 1}, \theta^{C 2}, \alpha\right\}$ where $\alpha$ is the actuarially fair premium. With a competitive insurance market, the equilibrium contract will be the one that maximizes consumer's expected utility subject to an actuarial fairness constraint. For future reference, the first order conditions corresponding to this equilibrium include:

$$
\begin{gathered}
U_{H}\left(q^{* G}, \theta\right)-\lambda c^{G}=0 \text { if } \theta \in\left[\theta^{C 1}, \theta^{C 2}\right] \\
U_{H}\left(q^{* S}, \theta\right)-\lambda c^{S}=0 \text { if } \theta \in\left[\theta^{C 2}, \theta^{L}\right]
\end{gathered}
$$

\footnotetext{
${ }^{8}$ Baumgardner (1991) is an early paper that characterizes managed care plans as insurance that uses specified quantities of care, rather than patient cost-sharing, as a way of limiting costs.

${ }^{9}$ As discussed further on, in the model of imperfect information, the contract will not specify a critical value $\theta^{C 1}$ (a point after which the patient is allowed to consume GP care) as it is not credibly enforceable.
} 


$$
\begin{gathered}
U\left(q^{* G}\left(\theta^{C 1}\right)\right)-U\left(q^{* N}\left(\theta^{C 1}\right)\right)-\lambda\left(F^{G}+c^{G} q^{* G}\left(\theta^{C 1}\right)\right)=0 \\
U\left(q^{* S}\left(\theta^{C 2}\right)\right)-U\left(q^{* G}\left(\theta^{C 2}\right)\right)-\lambda\left(F^{S}+c^{S} q^{* S}\left(\theta^{C 2}\right)-F^{G}-c^{G} q^{* G}\left(\theta^{C 2}\right)\right)=0
\end{gathered}
$$

where $q^{* j}\left(\theta^{C 1}\right), j=N, G$ denotes the optimally chosen level of care at $\theta^{C 1}$ when the provider is $N$ or $G, q^{* j}\left(\theta^{C 2}\right), j=G, S$ denotes the optimally chosen level of care at $\theta^{C 2}$ when the provider is $G$ or $S$ and where $\lambda$ is the Lagrange multiplier associated with actuarial fairness constraint given by:

$$
\alpha=\int_{\theta}\left[F^{j}+c^{j} q^{j}(\theta)\right] d F(\theta)
$$

A plan characterized by (13) to (17) is equivalent to a set of state-contingent contracts for health services. By itself, such a plan is not sufficient for attaining a first-best optimum in a conventional sense since a first-best optimum also requires that consumers be able to enter into state-contingent contracts for consumption as well as for health services. But if $\theta$ is indeed costlessly observable, there is no reason why such contracts couldn't exist. For example, state-specific consumption levels could be optimally chosen via state-contingent premium adjustments, making $\alpha$ function of $\theta, \alpha(\theta)$. If such contract were possible, the first-best optimum would be attainable.

\subsection{Information asymmetry}

In general, of course, the assumption that the patients' illness state is costlessly observable to either the insurer or the patient is not realistic, and first-best state-contingent contracts do not exist. However, real-world managed care contracts retain the principle of putting restrictions on the patient's right to choose which provider to use, and what quantity of services to utilize. In managed-care plans, the latter decisions are effectively made by physicians who are under contract with these plans. Cost control is accomplished by specifying the latter contracts in such a way that the physicians have an incentive to limit utilization and control aggregate costs.

In this paper, we assume that physicians in managed-care plans, whether primary-care physicians or hospital-based doctors, are paid through capitation or salary. Both forms of payment imply an incentive to limit the quantity of services supplied to each patient, since each unit of service involves a cost to the doctor (in the form of time and effort), but results in no additional income. 
However, as noted in the introduction, it also involves an incentive on primary-care physicians to refer patients to hospital whenever they are able to do so.

If patients cannot observe precisely their illness severity parameter $\theta$, physicians on capitation or salary have an incentive to exploit their superior information by downplaying the seriousness of the patient's illness and supply fewer services than the patient would utilize if he or she were fully informed. ${ }^{10}$ As in the previous model, patients, realizing this, will disbelieve their doctors' advice. In this case however, they cannot react by selecting a quantity different from that implied by the doctor's advice.

As in the previous section, suppose that patients can only tell in which of a series of intervals of the form $\left[\theta^{l-1}, \theta^{l}\right]$ their illness severity parameter falls. An implication of this information structure is that there is no point for insurance contracts to specify more than one value of $q$ for any interval and provider. (Given the doctor's incentive, the patient would always assume that the doctor would provide the lowest amount specified for that interval.) As a result, the equilibrium contract would, with one exception only, specify a single quantity of treatment in each interval.

The exception is the interval containing the critical value $\theta^{C 2}$ (where the patient first seeks inhospital care) which we have denoted $r^{2}$. Although a general practitioner paid by capitation has an incentive to refer a patient anywhere in this interval to hospital, hospital doctors are also assumed to observe the patient's true illness severity $\theta$. They can therefore refuse to accept patients with a $\theta$ below a contractually specified level. ${ }^{11}$ For this reason, a managed care contract can credibly specify a critical $\theta^{C 2}$ in this interval such that the patient will be treated in hospital if and only if the $\theta$ observed by the doctor is above that level, as well as separate quantities to be supplied depending on where the patient is treated. Under imperfect information, a contact cannot credibly specify $\theta^{C 1}$ (the illness severity at which a consumer would first be allowed to seek medical treatment) as the physician would always have an incentive to refuse treatment (within the critical interval) by reporting an illness severity below $\theta^{C 1}$. Formally, therefore the insurance contract in this case will take on the following form:

$$
\left\{q_{l}^{G}\left(l=r^{1}, \ldots, r^{2}-1\right), q_{r^{2}}^{G}, \theta^{C 2}, q_{r^{2}}^{S}, q_{l}^{S}\left(l=r^{2}+1, \ldots, L\right) ; \alpha\right\}
$$

\footnotetext{
${ }^{10}$ We assume implicitly that neither patients, nor the insurance provider, can infer ex post whether or not the treatment was appropriate (within each illness class).

${ }^{11}$ Note that hospital-based specialists are also paid by capitation and also have an incentive to treat as few patients as possible.
} 
where $\alpha$ is the actuarially fair premium defined by (17).

As before, if the insurance market is competitive, the equilibrium contract is the one that maximizes the representative consumer's expected utility, subject to the actuarial fairness constraint. The necessary first order conditions are:

$$
\int_{\theta^{l-1}}^{\theta l} U_{H}\left(q_{l}^{j}, \theta\right) d F(\theta)-\lambda\left(F^{j}+c^{j} q_{l}^{j}\right) P(l)=0
$$

for $l=r^{1}, \ldots, r^{2}-1, r^{2}+1, \ldots, L$ and $P(l)=\int_{\theta^{l-1}}^{\theta^{l}} d F(\theta)$ and where $j=G$ for $r^{1}+1, \ldots, r^{2}-1$ and $j=S$ for $r^{2}+1, \ldots, L$

$$
\begin{gathered}
\int_{\theta^{r^{2}-1}}^{\theta^{C 2}} U_{H}\left(q_{r^{2}}(G), \theta\right) d F(\theta)-\lambda\left(F^{G}+c^{G} q_{r^{2}}(G)\right) P\left(r^{2}, G\right)=0 \\
\int_{\theta^{C 2}}^{\theta^{r^{2}}} U_{H}\left(q_{r^{2}}(S), \theta\right) d F(\theta)-\lambda\left(F^{S}+c^{S} q_{r^{2}}(S)\right) P\left(r^{2}, S\right)=0
\end{gathered}
$$

where $P\left(r^{2}, G\right)$ is the proportion of patients that fall in that interval $r^{2}$ who use general care and where $P\left(r^{2}, S\right)$ is the proportion of patients that fall in that interval $r^{2}$ that use in-hospital specialty care.

$$
U\left(q_{r^{2}}\left(\theta^{C 2}, S\right)\right)-U\left(q_{r^{2}}\left(\theta^{C 2}, G\right)\right)-\lambda\left(F^{S}+c^{S} q_{r^{2}}\left(\theta^{C 2}, S\right)-F^{G}-c^{G} q_{r^{2}}\left(\theta^{C 2}, G\right)\right)=0
$$

and the actuarial fairness constraint $(\alpha)$ given by (17).

Clearly, a contract of this form will yield an expected utility that is lower than in the full information case. A more interesting question is whether it will yield a higher expected utility than the second-best optimal conventional contract under information asymmetry. As in the case with observable illness severity parameters, this cannot be guaranteed in general if there are no statecontingent markets in consumption. However, there is no reason why a managed-care contract of this form could no specify, for each interval, both a quantity $q_{l}^{j}$ of medical services, and an associated premium adjustment. Formally, this would be equivalent to specifying a schedule of net premiums $\alpha_{l}, l=1, \ldots, L$. We then have:

Proposition 7 Under imperfect information, the optimal managed-care contact of the form (18) with optimally chosen interval-specific premiums $\alpha_{l}$ yields higher expected utility than the optimal conventional contract of the form $\{\alpha, \beta(\alpha)\}$. 
Proof: Under a conventional contract with imperfect information, the values of health services utilization and consumption are both constant in each interval $l$, but are chosen so as to satisfy restriction of the form (11). With a managed-care contract with interval-specific premiums, the constant levels of health services utilization and consumption in each interval can be optimally chosen without restrictions.

Proposition 7 would still be true if consumers in conventional plans always knew whether or not their illness severity parameter $\theta$ were above or below the optimum critical value of $\theta^{C 2}$ and could choose appropriately among providers in the $r^{2}$ interval. In practice, however, a substantial part of the efficiency gains achievable through a second-best optimal managed care plan of the form (18) may be due to the fact that consumers in conventional plans do not know where in the $r^{2}$ interval they are and, as a result, can only choose one type of provider in that interval. If they consistently choose $S$ (that is, choose in-hospital specialty care), total costs are likely to be considerably higher than they would be if those below $\theta^{C 2}$ would choose $G$. Indeed, studies of the reason why HMOs in the US are able to provide care at costs below those of conventional plans have pointed to less utilization of hospital services as an important part of the explanation.

\section{Conclusion}

In this paper we have extended the analysis of the interaction between insurance and health services utilization to the case where there is a choice for consumers with different illness severity not only with respect to the quantities of services to utilize, but also among types of providers with different cost conditions; our main example has been the choice between outpatient primary-care physicians and treatment in hospital.

Our analysis shows that consideration of the patient's incentive to choose between outpatient and hospital care is important for finding the efficient degree of patient cost sharing in models of second-best optimal conventional insurance: That patients with lower degrees of cost sharing have too little of an incentive to choose the lowest-cost provider. This loss is in addition to that associated with the tendency of consumers with lower cost sharing to overutilize services from given providers.

Generally this result holds as well when it is assumed that there is information asymmetry between patients and providers, even though in this case outpatients providers paid via fee for 
service may have an incentive to understate patients' illness severity in certain circumstances, in order to discourage them from seeking hospital care.

We also consider the case where insurance takes the form of prepayment plans in which the quantity of care in different states is not chosen by the patient but is specified in the insurance contract. If it is assumed that the patient's illness state is costlessly observable by patients and insurers as well as by doctors, it is possible to design a prepayment plan of this form that is first-best optimal both in the sense of making patients utilize the efficient volume of services given the choice of provider, and to choose efficiently between the two kinds of provider in given illness states.

If there is asymmetric information in the sense that illness severity cannot be perfectly observed by patients and insurers, first-best prepayment contracts cannot be credibly enforced. However, second-best prepayment plans can be designed through managed-care contracts under which providers are subject to supply-side incentives to control service utilization (for example, by being paid through salary or capitation), and the quantity of care promised under the plan is contingent on the consumers' (imperfect) information regarding their illness severity. Although any such plan clearly must yield lower expected utility than a first-best prepayment plan would, we find that a second-best optimal managed care plan may dominate (under certain condition) a second-best optimal conventional plan with cost control through demand-side cost sharing.

Although we believe that these results are of considerable interest, their significance of course is tempered by the restrictiveness of the assumptions built into the models from which they are derived. In particular, the assumption that all consumers face the same probability distribution for the illness severity parameter rules out consideration of problems with cream skimming and adverse selection. Another important assumption is that even in the cases where patients and insurers cannot observe precisely the patient's illness severity parameter, they can observe the quantities of services that providers render. If these quantities are imperfectly observable as well, the superiority of managed care plans over conventional insurance is no longer guaranteed.

\section{References}

[1] Arrow, K.J.(1963) 'Uncertainty and the Welfare Economics of Medical Care,'American Economic Review 53, 941-69 
[2] Baumgardner, J. (1991) 'The interaction between forms of insurance contracts and types of technical change in medical care,' Rand Journal of economics 22, 36-53

[3] Blomqvist, Å. (1991) 'The doctor as a double agent: Information asymmetry, health insurance and medical care,' Journal of Health Economics 10, 411-32

[4] Bradford, W., and R. Martin (1996) 'An Economic Theory of Referrals: Applications to the Medical Profession,' University of New Hampshire Department of Economics Working Paper

[5] d'Arc Taylor, C., S. M. Polich, C.E. Peterson, and E.M. Sloss (1987) 'Volume 3: User's Guide to HIE Data,' HIE Reference Series, The Rand Corporation

[6] Dranove, D. (1998) 'Demand inducement and the physician/patient relationship,'Economic Inquiry 26, 281-98

[7] Ellis, R.P. and Thomas McGuire (1986) 'Provider behavior under prospective reimbursement,' Journal of Health Economics 5, 121-51

[8] Evans, R.G. (1974) 'Supplier-induced demand: some empirical evidence and implications,' in The Economics of Health and Medical Care, ed. M. Perlman (London: MacMillan)

[9] Forrest, C.B., and Reid (1997) 'Passing the Baton: HMOs' Influence On Referrals To Specialty Care,' Health Affairs 16, 151-62

[10] Frank, P. and C.M. Clancy (1997) 'Referrals of Adult Patients from Primary Care: Demographic Disparities and Their Relationship to HMO insurance,' The Journal of Family Practice $45,47-53$

[11] Glazer, J., and T.G. McGuire (1992) 'The Economics of Referrals,' Boston University Industry Studies Program Discussion Paper Series: 20

[12] Glenn, J.K., F.H. Lawler, and M.S. Hoerl (1987) 'Physician Referrals in a Competitive Environment: An estimate of the Economic Impact of a Referral,' Journal of the American Medical Association 258, 1920-23

[13] Grembowski, D.E., K. Cook, D.L. Patrick, and A.E. Roussel (1998) 'Managed Care and Physician Referral,' Medical Care Research and Review 55, 3-31 
[14] Hillman, A.L., M.V. Pauly, and J.J. Kerstein (1989) 'How financial incentives affect physicians' clinical decisions and the financial performance of health maintenance organizations?,' New England Journal of Medicine 321, 86-92

[15] Hurley, R.E., D.A. Freund, and B.J. Gage (1991) 'Gatekeeper Effects on Patterns of Physician Use,' The Journal of Family Practice 32, 167-74

[16] Léger, P.T. (2000) 'Quality control mechanisms under capitation payment for medical services,' Canadian Journal of Economics 33, 564-86

[17] Manning, W.G., J.P. Newhouse, N.Duan, E.B. Keeler, A.Leibowitz, and M.S. Marqui (1987) 'Health Insurance and the Demand for Medical Care: Evidence from a Randomized Experiment,' American Economic Review 77, 251-277

[18] Martin, R.P., P. Diehr, K.F. Price, and W.C. Richardson (1989) 'Effect of a Gatekeeper Plan on Health Services Use and Charges: A Randomized Trial,' American Journal of Public Health $79,1628-32$

[19] Newhouse, J.P. and the Insurance Experiment Group (1993) Free For All? Lessons from the RAND Health Insurance Experiment (Cambridge: Harvard University Press)

[20] Pauly, M.V. (1979) 'The ethics and economics of kickbacks and fee splitting,' Bell Journal of Economics 10, 344-52

[21] Rochaix, Lise (1989) 'Information Asymmetry and Search in the Market for Physicians' services,' Journal of Health Economics 8, 53-84

[22] Shea, D., B. Stuart, J.Vasey, and S. Nag (1999) 'Medical Physician Referral Patterns,' HSR: Health Services Research 34, 332-48

[23] Shortell, S. (1972) 'A model of physician referral behavior: a test of exchange theory in medical practice,' Center for Health Administration Studies, University of Chicago, Research Serices 31

[24] Stearns, S.C., B.L.Wolfe, and D.A. Kindig (1992) 'Physician response to fee-for-service and capitation payment,' Inquiry 29, 416-25 
[25] Wolinsky, A. (1993) 'Competition in a market for informed experts' servces,' RAND Journal of Economics 24, 380-398

\section{Appendix}

\subsection{Appendix 1}

Proof that $\frac{\partial g}{\partial \theta}>0$.

We know that by the implicit function theorem that $\frac{\partial q}{\partial \theta}=-\frac{F_{\theta}}{F_{q}}$.

Where,

$$
F_{\theta}=\beta c U_{X H}(., .)-U_{H H}(., .)>0
$$

if $U_{X H}(.,) \geq$.0 and $U_{H H}(.,)<$.0 .(Sufficient but not nessary)

and where,

$$
-F_{q}=-(\beta c)^{2} U_{X X}(., .)+\beta c\left(U_{X H}(., .)+U_{H X}(., .)\right)-U_{H H}(., .)>0
$$

if $U_{X X}(.,)<0,. U_{H H}(.,)<$.0 , and $U_{X H}(.,)=.U_{H X}(.,) \geq$.0 . (Sufficient but not necessary) Thus, $\frac{\partial q}{\partial \theta}>0$. Q.E.D.

\subsection{Appendix 2}

Proof that $\frac{\partial q}{\partial \beta}<0$.

We know that by the implicit function theorem that $\frac{\partial q}{\partial \theta}=-\frac{F_{\beta}}{F_{q}}$.

From appendix 1 we know that $F_{q}>0$ if $U_{X X}(.,)<0,. U_{H H}(.,)<$.0 and $U_{X H}(.,)=.U_{H X}(.,$. 0. (Sufficient but not necessary).

and,

$$
F_{\beta}=c U_{X}(., .)-\beta c U_{X X}\left(F+c q+\alpha^{\prime}(\beta)\right)+U_{H X}(., .)\left(F+c q+\alpha^{\prime}(\beta)\right)>0
$$

if $U_{H X}(.,) \geq$.0 and $F+c q \geq \alpha^{\prime}(\beta)$ (Sufficient but not necessary).

Thus $\frac{\partial q}{\partial \beta}<0$. Q.E.D. 


\subsection{Appendix 3}

Recall that $\theta^{C 1}$ is defined as the illness severity where:

$$
U^{N} \equiv U\left(I-\alpha,-\theta^{C 1}\right)=U\left(I-\alpha-\beta\left(F^{G}+c^{G} q^{G *}\right), q^{G *}-\theta^{C 1}\right) \equiv U^{G}
$$

As a result, points 'a' and 'b' (represented on figure 2) both lie on the same compensated demand curve for the critical point $\theta^{C 1}$, which we label $D\left(\beta c ; \alpha, \theta^{C 1}\right)$. The shaded consumer surplus area in the diagram must equal the difference in out-of-pocket expenses attributable to the fixed costs between GP care and no care at all. That is, it must be the case that

$$
\beta F^{G}=\int_{\beta c^{G}}^{\infty} D\left(\beta c ; \alpha, \theta^{C 1}\right) d(\beta c)=\beta \int_{c^{G}}^{c^{\infty}} D\left(\beta c ; \alpha, \theta^{C 1}\right) d c
$$

where the second equality is derived using standard change-of-variable techniques. If $\beta$ falls, the value of the integral on the right hand side will increase (since $\partial D / \partial \beta c)<0$ ), for given $\alpha$ and $\theta^{C 1}$. Thus, for given $\alpha$, equality must occur at a smaller value of $\theta^{C 1}$ since $\partial D / \partial \theta>0$.

$<$ Insert figure 2 here $>$

Furthermore, recall that $\theta^{C 2}$ is defined as the illness severity where:

$$
U^{G} \equiv U\left(I-\alpha-\beta\left(F^{G}+c^{G} q^{G *}\right), q^{G *}-\theta^{C 2}\right)=U\left(I-\alpha-\beta\left(F^{S}+c^{S} q^{S *}\right), q^{S *}-\theta^{C 2}\right) \equiv U^{S}
$$

As a result, points 'a' and 'b' (represented on figure 3) both lie on the same compensated demand curve for the critical point $\theta^{C 2}$, which we label $D\left(\beta c ; \alpha, \theta^{C 2}\right)$. The shaded consumer surplus area in the diagram must equal the difference in out-of-pocket expenses attributable to the fixed costs between in-hospital care and GP care. That is, (using the same change-of-variable technique as above), it must be the case that

$$
\beta\left(F^{S}-F^{G}\right)=\int_{\beta c^{s}}^{\beta c^{G}} D\left(\beta c ; \alpha, \theta^{C 2}\right) d(\beta c)=\beta \int_{c^{S}}^{c^{G}} D\left(\beta c ; \alpha, \theta^{C 2}\right) d c .
$$

If $\beta$ falls, the value of the integral on the right hand side will increase, for given $\alpha$ and $\theta^{C 2}$. Thus, for given $\alpha$, equality must occur at a smaller value of $\theta^{C 2}$.

$<$ Insert figure 3 here $>$ 
Figure 1:

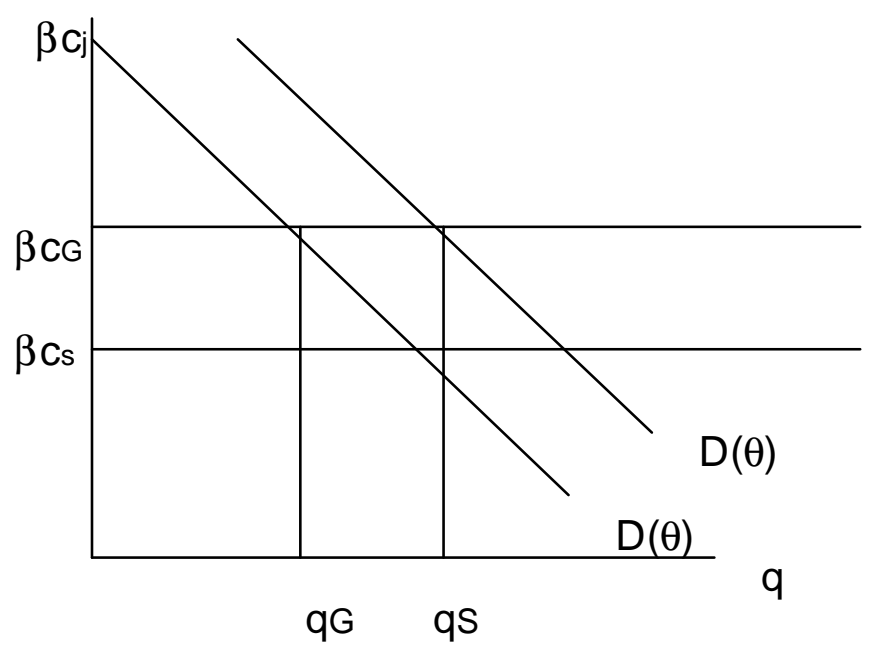

Figure 2:

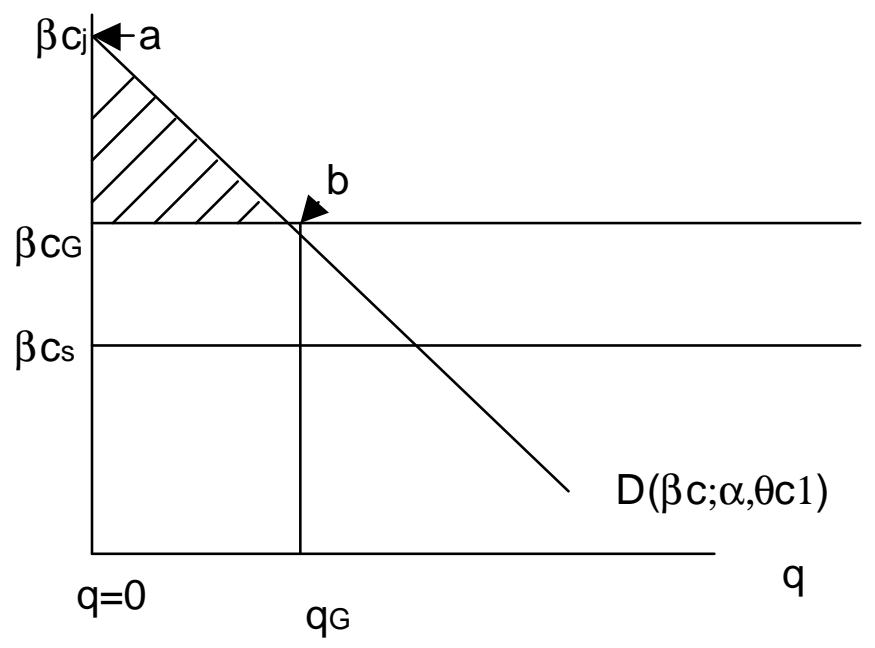


Figure 3 :

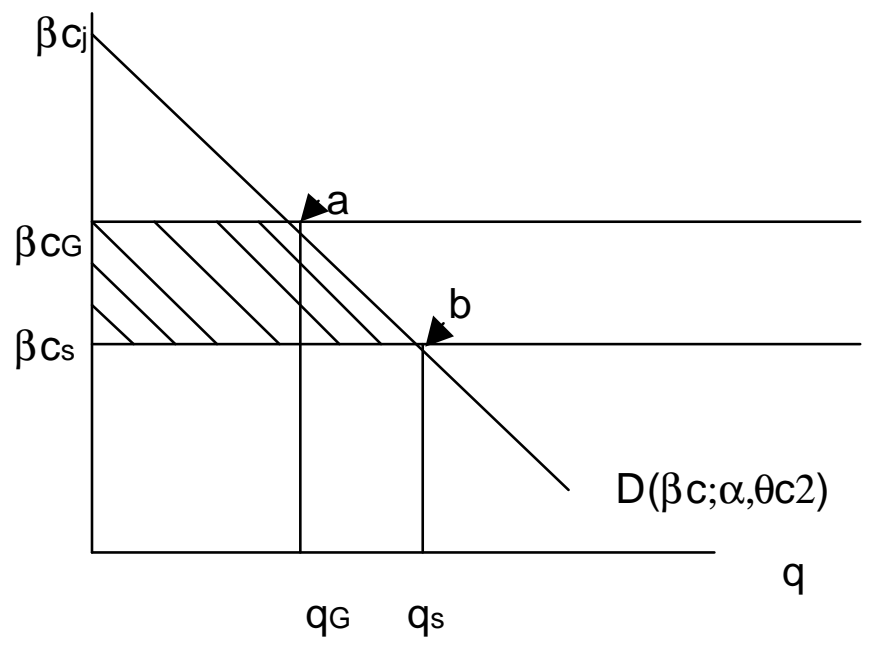




\section{Liste des publications au CIRANO*}

Série Scientifique / Scientific Series (ISSN 1198-8177)

2002s-06 Information Asymmetry, Insurance, and the Decision to Hospitalize / Åke Blomqvist et Pierre Thomas Léger

2002s-05 Coping with Stressful Decisions: Individual Differences, Appraisals and Choice / Ann-Renée Blais

2002s-04 A New Proof Of The Maximum Principle / Ngo Van Long et Koji Shimomura

2002s-03 Macro Surprises And Short-Term Behaviour In Bond Futures / Eugene Durenard et David Veredas

2002s-02 Financial Asset Returns, Market Timing, and Volatility Dynamics / Peter F. Christoffersen et Francis X. Diebold

2002s-01 An Empirical Analysis of Water Supply Contracts / Serge Garcia et Alban Thomas

2001s-71 A Theoretical Comparison Between Integrated and Realized Volatilities Modeling / Nour Meddahi

2001s-70 An Eigenfunction Approach for Volatility Modeling / Nour Meddahi

2001s-69 Dynamic Prevention in Short Term Insurance Contracts / M. Martin Boyer et Karine Gobert

2001s-68 Serial Cost Sharing in Multidimensional Contexts / Cyril Téjédo et Michel Truchon

2001s-67 Learning from Strike / Fabienne Tournadre et Marie-Claire Villeval

2001s-66 Incentives in Common Agency / Bernard Sinclair-Desgagné

2001s-65 Detecting Mutiple Breaks in Financial Market Volatility Dynamics / Elena Andreou et Eric Ghysels

2001s-64 Real Options, Preemption, and the Dynamics of Industry Investments / Marcel Boyer, Pierre Lasserre, Thomas Mariotti et Michel Moreaux

2001s-63 Dropout, School Performance and Working while in School: An Econometric Model with Heterogeneous Groups / Marcel Dagenais, Claude Montmarquette et Nathalie Viennot-Briot

2001s-62 Derivatives Do Affect Mutual Funds Returns : How and When? / Charles Cao, Eric Ghysels et Frank Hatheway

2001s-61 Conditional Quantiles of Volatility in Equity Index and Foreign Exchange Data / John W. Galbraith, Serguei Zernov and Victoria Zinde-Walsh

2001s-60 The Public-Private Sector Risk-Sharing in the French Insurance "Cat. Nat. System" / Nathalie de Marcellis-Warin et Erwann Michel-Kerjan

2001s-59 Compensation and Auditing with Correlated Information / M. Martin Boyer et Patrick González

2001s-58 Resistance is Futile: An Essay in Crime and Commitment / M. Martin Boyer

* Consultez la liste complète des publications du CIRANO et les publications elles-mêmes sur notre site Internet : 
2001s-57 The Unreliability of Output Gap Estimates in Real Time / Athanasios Orphanides et Simon van Norden

2001s-56 Exact Nonparametric Two-Sample Homogeneity Tests for Possibly Discrete Distributions / Jean-Marie Dufour et Abdeljelil Farhat

2001s-55 Les coûts de la réglementation : une revue de la littérature / Robert Gagné, Paul Lanoie, Pierre-Carl Micheud et Michel Patry

2001s-54 Testing for structural Change in the Presence of Auxiliary Models / Eric Ghysels et Alain Guay

2001s-53 Environmental Regulation and Productivity: New Findings on the Porter Hypothesis / Paul Lanoie, Michel Patry et Richard Lajeunesse

2001s-52 The Aftermarket Performance of Initial Public Offerings in Canada / Maher Kooli et Jean-Marc Suret

2001s-51 Capital Structure and Risk Management / Karine Gobert

2001s-50 The Underpricing of Initial Public Offerings: Futher Canadian Evidence / Maher Kooli et Jean-Marc Suret

2001s-49 How Innovative Are Canadian Firms Compared to Some European Firms? A Comparative Look at Innovation Surveys / Pierre Mohnen et Pierre Therrien

2001s-48 A Tale of Two Ports / Ngo Van Long et Kar-yiu Wong

2001s-47 Wage Policy of Firms: An Empirical Investigation / Stéphanie Lluis

2001s-46 Forecasting Some Low-Predictability Time Series Using Diffusion Indices / Marc Brisson, Bryan Campbell et John W. Galbraith

2001s-45 The Importance of the Loss Function in Option Pricing / Peter Christoffersen et Kris Jacobs

2001s-44 Let's Get "Real" about Using Economic Data / Peter Christoffersen, Eric Ghysels et Norman R. Swanson

2001s-43 Fragmentation, Outsourcing and the Service Sector / Ngo Van Long, Ray Riezman et Antoine Soubeyran

2001s-42 Nonlinear Features of Realized FX Volatility / John M. Maheu et Thomas H. McCurdy

2001s-41 Job Satisfaction and Quits: Theory and Evidence from the German Socioeconomic Panel / Louis Lévy-Garboua, Claude Montmarquette et Véronique Simonnet

2001s-40 Logique et tests d'hypothèse : réflexions sur les problèmes mal posés en économétrie / Jean-Marie Dufour

2001s-39 Managing IT Outsourcing Risk: Lessons Learned / Benoit A. Aubert, Suzanne Rivard et Michel Patry

2001s-38 Organizational Design of R\&D Activities / Stefan Ambec et Michel Poitevin 